\title{
Research on maintenance support system of civil military integration equipment based on DODAF
}

\author{
Dunxiang Zhua , Xianming Shi, Zhixin Ma, and Lixin Wang, \\ Mechinical engineering college, Shijiazhuang050000, China; \\ a2267895911@qq.com,
}

\begin{abstract}
Keywords: DODAF, Civil Military Integration, Equipment Maintenance Support, System, View
\end{abstract} Mode.

\begin{abstract}
To strengthen the civil military integration under the background of the equipment maintenance support system for equipment, according to military and civilian integration organizational factors, maintenance process, operation mechanism, using the DODAF method, from a comprehensive overview, ability to develop, top-level design, three aspects of model building, forming a equipment maintenance support system framework of civil military integration. The results can provide reference for the decision makers and equipment maintenance personnel.
\end{abstract}

\section{Introduction}

With the orderly promotion of civil military integration, the scope of its application gradually expanded to the field of equipment maintenance support. The maintenance support of military and civilian integration equipment plays an important role in strengthening the maintenance support, giving full play to the civil resources, reducing the maintenance cost, improving the maintenance support ability and ensuring the benefit.

In the research of military and civilian integration equipment maintenance support system, many scholars have carried on the thorough discussion. Sun Zhiming ${ }^{[1]}$ for the integration of military and civilian equipment maintenance operation mechanism, analyzes the shortcomings and the running status of the system, and put forward the corresponding improvement measures; Zhao Ming ${ }^{[2]}$ from the view of system science, analyzes the main civil military integration equipment maintenance support system of the object, and on the structure and function are described; Chen Yonglong ${ }^{[3]}$ looks on the connotation of civil military integration maintenance support system analysis, summarized the guiding ideology and basic principles of system construction, and clear the contents of construction organization system, power system, reserve system and personnel system; Li Guizheng ${ }^{[4]}$ combined with the development of equipment and the evolution of warfare, focusing on the core competence of the integration of military and civilian equipment maintenance support system development.

The military and civilian integration equipment maintenance system structure is more complex, and the diversity of the maintenance support and maintenance support object makes the maintenance support face greater resistance ${ }^{[5]}$. With the promotion of the United States Defense Architecture Framework (DODAF), it plays a more and more important role in the construction of system architecture $^{[6]}$. In this paper, the DODAF method is used to establish a clear military and civilian integration maintenance support system, which is of great significance to clarify the relationship between the system framework and promote the orderly operation of the maintenance support system.

\section{Introduction to the DODAF Framework}

DODAF (Department of Defense Architecture Framework) is developed by the US Department of defense to provide top, promote development concept, the architecture team guidelines, best practices and methods of collection, as the overall structure of command and management ability and decision-making processes in domain ${ }^{[7]}$. DODAF can provide operational decisions, joint capabilities integration and development decisions, unified procurement decisions, planning or development roadmap research and development services. DODAF1.0 has now been updated to DODAF2.02, the 
core includes 8 views and 52 modules. In this paper, the maintenance support system of military and civilian integration equipment based on is established DODAF ${ }^{[8]}$.

\section{Military and Civilian Integration Equipment Maintenance Support System Viewpoint Model}

Through the use of DODAF architecture, starting from different viewpoint, constructing AV-1, CV-1, OV-1, OV-2, OV-3, OV-4a, OV-4b model of civil military integration equipment maintenance support system, planning and design framework of the integration of military and civilian equipment maintenance support system.

\subsection{Comprehensive Summary Model (AV-1)}

In view of the integration of military and civilian equipment maintenance support, starting from the integration of military and civilian purposes, the background, and analyzes the application scope and constraints, and pointed out that the expected effect of the integration of military and civilian status of equipment maintenance and can achieve the realization of extension.

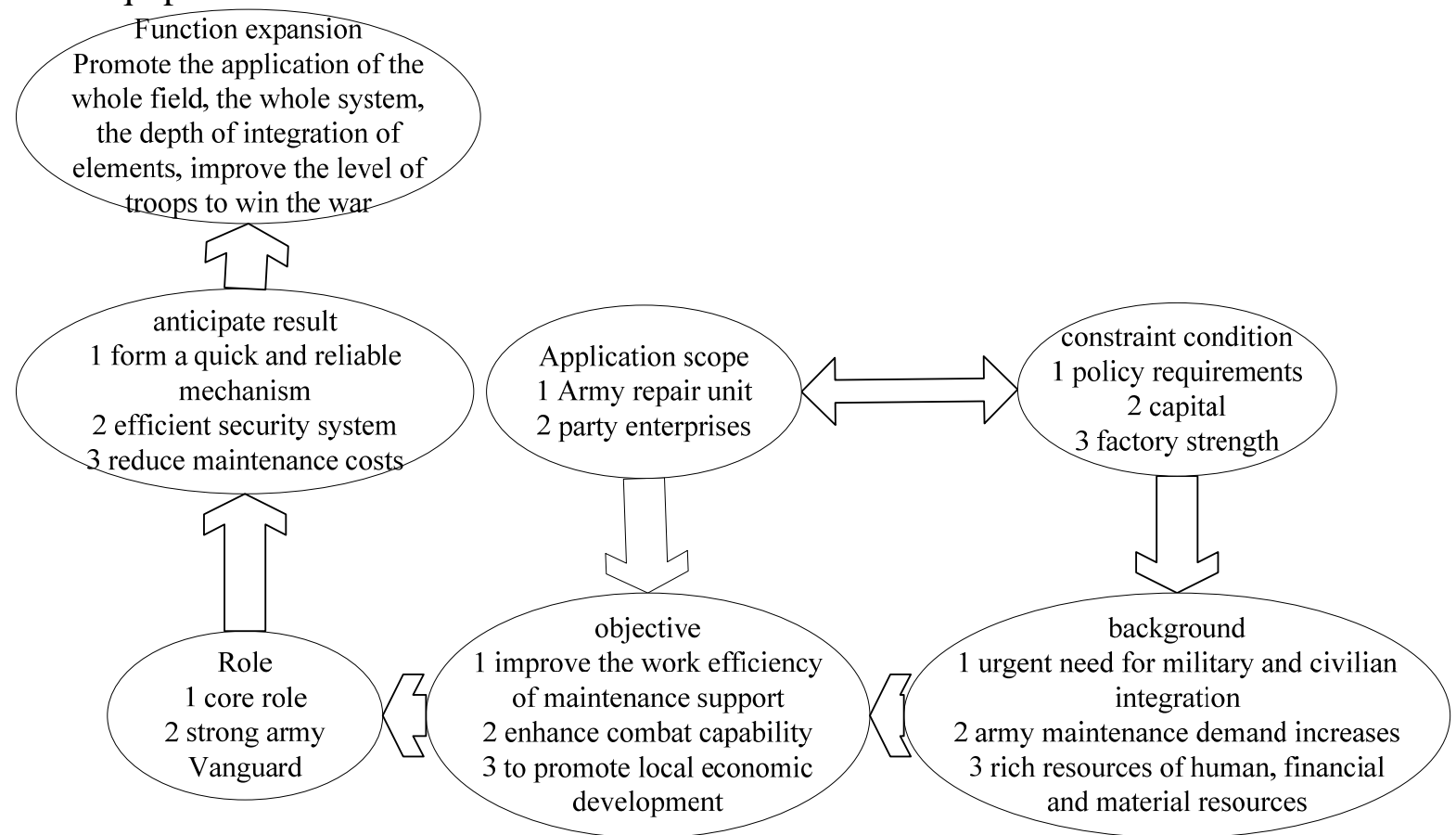

Figure 1. military and civilian integration equipment maintenance comprehensive summary model (AV-1)

\subsection{Military and Civilian Integration Equipment Maintenance Support Capability (CV-1) Concept Model}

The three stages of the time dimension can be established based on the integration of military and civilian equipment maintenance support process DODEF model, namely the integration of military and civilian equipment maintenance support capability model (CV-1), put forward the overall idea, clear objectives in each stage, to clarify the ability of civil military integration in various stages of the equipment maintenance support needed to be targeted. 


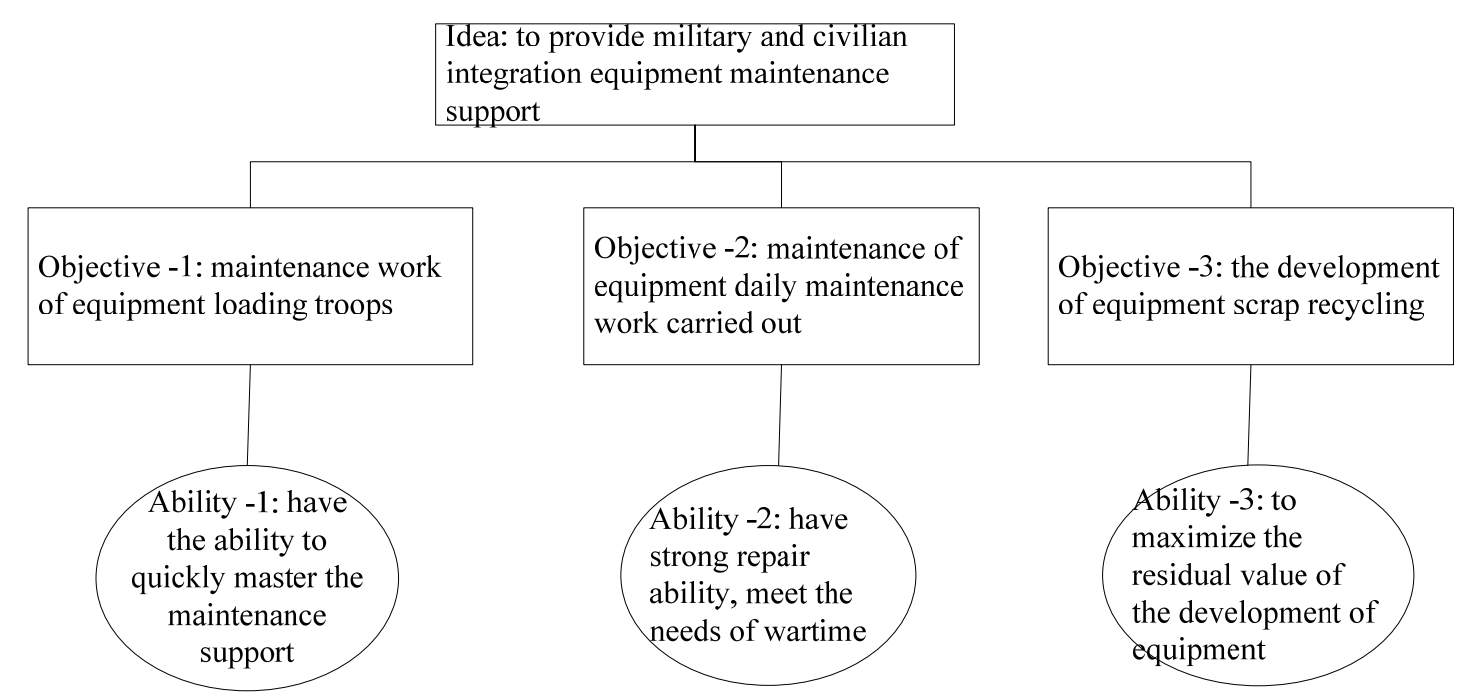

Figure 2. military and civilian integration equipment maintenance support capability (CV-1) concept model

From Figure 2, the integration of military and civilian equipment maintenance support capability is conceived through multi subject participation, through the erection of civil military integration system maintenance work of equipment, in the formulation of laws and regulations, carry out military coordination, establish military production plan and contract doctrine, organization during wartime management, guide the integration of military and civilian equipment maintenance work carried out more. Timely and effectively provide combat capability.

\subsection{Top Operational Concept Map}

\subsubsection{Military and Civilian Integration Equipment Maintenance Support Advanced Concept Map (OV-1)}

The integration of military and civilian equipment maintenance support advanced concept map as shown in Figure 3, mainly in the modern information war, operation and maintenance personnel and maintenance personnel, command of professional management personnel, civilian enterprises, research institutions together to complete the equipment to repair the damage. Maintenance of command personnel allocation of maintenance tasks, according to the extent of the damage to equipment is to determine the order of priority of reasonable classification, on-site repair, replacement or on-site evacuation; warehouse personnel promptly communicate with maintenance personnel, according to the equipment, material consumption of equipment before, to ensure the maintenance and guarantee adequate equipment; colleges and scientific research units for the new column the army is most familiar with operation and maintenance personnel to explain, make maintenance operators master maintenance skills as soon as possible, maintenance personnel should also grasp the opportunities and scientific research units college personnel to exchange experience; professional management personnel is mainly responsible for the maintenance of operating personnel training; the party the main production enterprises and maintenance support for general equipment. At the end of the contract period shall be referred to the task of maintenance operations personnel and equipment for protection as soon as possible. Joint security part, should also fully cooperate. 


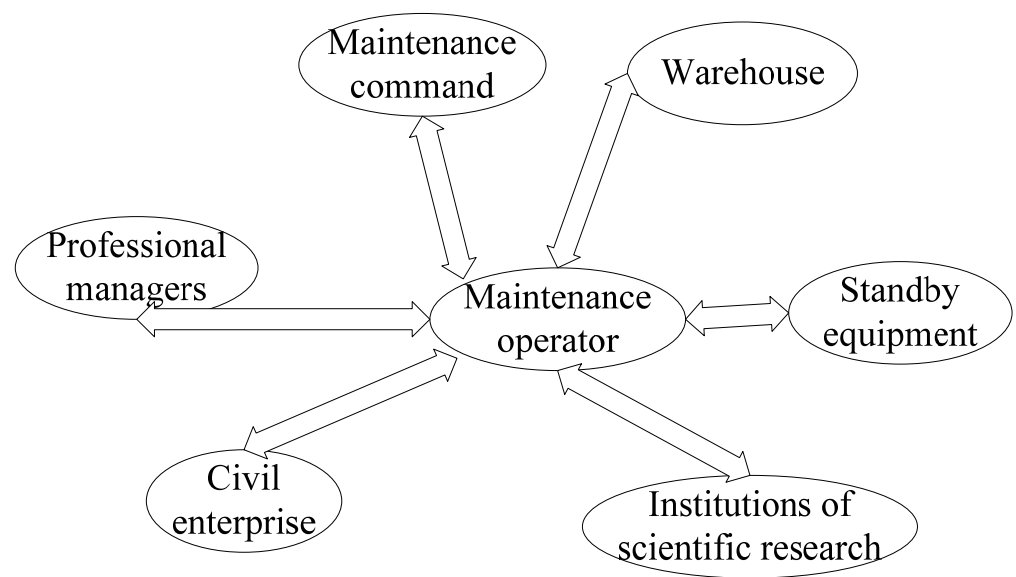

Figure 3. Military and civilian integration equipment maintenance support advanced concept map

\subsubsection{Combat Relationship View (Ov-2)}

(OV-1)

The relationship between operational relation view (ov-2) as shown in Figure 4, the unified command and coordination of military and civilian integration coordination office, the equipment maintenance tasks by universities and research institutes to develop plans and goals, organizing the party enterprises and military enterprises competitive bidding, materials and equipment supply and demand of audit of primary repair units, adjustment annual maintenance task. Through learning and research cooperation and civil enterprises, military enterprises, new equipment research and development, the improvement of existing equipment, repair the damaged equipment; the enterprises and military enterprises have the talent, technology resources, personnel training and technical guidance for Army primary repair unit; fault protection equipment based on layer repair feedback unit, promote research and improvement of equipment.

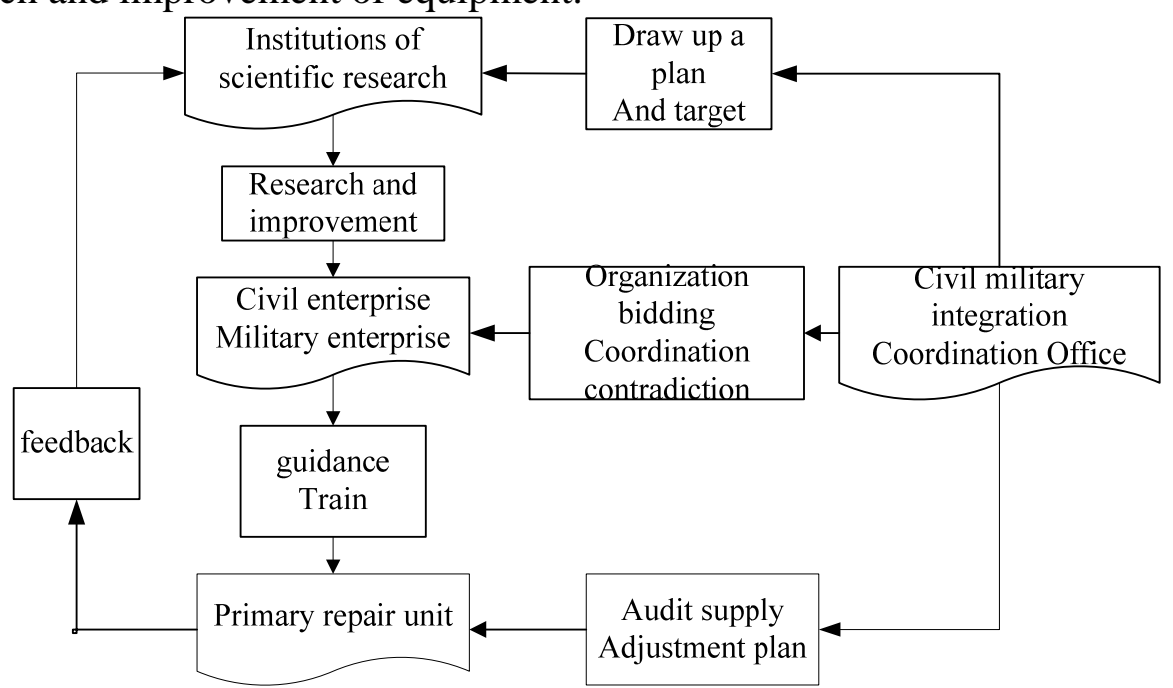

Figure 4. Combat relationship view (ov-2)

\section{Conclusion}

This paper discuss military and civilian integration organizational factors, maintenance process, operation mechanism, using the DODAF method, from a comprehensive overview, ability to develop ,top-level design, three aspects of model building, forming a equipment maintenance support system framework of civil military integration. The results can provide reference for the decision makers and equipment maintenance personnel. 


\section{References}

[1]. Sun Zhiming, Li Fengxue. Study on the operational mechanism of military and civilian integration equipment support system [J]. Journal of National Defense University,.2012 (3): 1

[2]. Sun Ming. Military and civilian integration equipment maintenance support system [M]. National Defense Industry Press.2014

[3]. Chen Yonglong, Li Fusheng. Research on military and civilian integration equipment support construction [J]. Journal of the Institute of equipment,.2012 (2): 37-40

[4]. Li guizheng . Discussion on the core competence construction of equipment maintenance support [J]. Air equipment.2011 (11): 25-26

[5]. Xiao Zhenhua, Lv Bin. Research on the ideal model of military and civilian integration equipment support [J]. Journal of Institute of equipment,.2013 (3): 22-26

[6]. Li Dong, Feng Ting. Analysis of military helicopter maintenance support information architecture based on DODAF [R]. Conference on aviation equipment maintenance technology and application. 2015

[7]. Zhang Shaobing, Guo Zhongwei. Combat system architecture of air defense command information system based on DODAF [J] Ordnance Industry Automation. 2013(3): 18-22

[8]. Kamal Chaharsooghi. Developing life-cycle phases for the DoDAF using ISO15704 Annex A (GERAM) [J]. Computers in Industry.2011 